\title{
Conductive Hearing Loss Due to Trauma
}

\author{
Olushola A. Afolabi, Biodun S. Alabi, \\ Segun Segun-Busari and Shuaib Kayode Aremu \\ University of Ilorin Teaching Hospital, Ilorin, Kwara State \\ Nigeria
}

\section{Introduction}

Hearing impairment is one of the most frequent sensory deficits in humans, affecting more than 250 million people in the world. Consequences of hearing loss include inability to interpret speech, often resulting in a reduced ability to communicate and delay in language acquisition. Untreated hearing loss may also cause economic and educational disadvantage, social isolation and cause stigmatization.

There are three basic types of hearing loss based on the part of auditory system with the damage: conductive hearing loss, sensorineural hearing loss, and mixed hearing loss.

Conductive hearing loss is the most common cause of hearing impairment both in children and in the adults and the incidence is significantly higher in children. In conductive hearing loss, the inner ear functions normally, but sound vibrations are blocked from passage through the ear canal, ear drum or across the tiny bones located in the middle ear. Patients with conductive hearing loss hear perceive bone-conducted sounds presented with a small vibrator to the skull with better thresholds than sounds presented through earphones. Conductive hearing loss is usually mild to moderate in degree and can be unilateral or bilateral and in most cases unilateral. Most type of conductive hearing loss is correctable by relatively minor medical or surgical treatments. More significant conductive hearing loss may be associated with skull and/or facial malformations which may require surgery for its correction.

Trauma generally is a major cause of morbidity and mortality in any society [Paul \& Peter 2001]. Generally, trauma to the ear may result in fracture of the external auditory canal, tympanic membrane perforation, fracture to the ossicular chains, fracture of the temporal bone itself, damage to the cochlea or the facial nerve. Lesser bone trauma causes damage to the ossicular chains [Fradis \& Podoshin 1975.] Hearing loss from trauma occurs in $22.5 \%$ of cases of temporal bone trauma and of these cases 16-30\% have conductive hearing impairment [Fradis \& Podoshin 1975, Ghoyareb B.Y et al 1987]. Hearing loss is defined as the averaged hearing loss at 1000, 2000 and $4000 \mathrm{~Hz}$, measured by pure tone audiometry. This definition, although different from WHO/ISO definitions, is currently used in Nigeria because of its higher relevance to speech discrimination. It also corresponds to the standard proposed by the British Association of Otolaryngology and the British Society of Audiology (1983). Hearing is said to be impaired when the hearing level is above $25 \mathrm{~dB}$ in the best ear. Hearing loss can have a profound impact on an individual's emotional, physical, and social well-being. People with hearing loss are more likely to report symptoms of depression, 
dissatisfaction with life, reduced functional health and withdrawal from social activities. This chapter aims to profile hearing loss due to trauma and its aetiology.

\subsection{Anatomy and physiology of conductive hearing loss due to trauma}

The ear consists of three parts namely external, middle and inner ear. Conductive hearing loss occurs due to damage to the external or middle ear (Figure 1).

The external ear consists of the pinna, and external auditory canal. The external auditory canal is about $2.5 \mathrm{~cm}$ long. The external auditory canal extends from the concha to the tympanic membrane. The middle ear is made up of the Tympanic cavity, Aditus ad-antrum, mastoid air cells and Eustachian tube. It contains the ossicles, nerves and muscles and extends from the medial end of the tympanic membrane to the stapes footplate (figure 1.0).

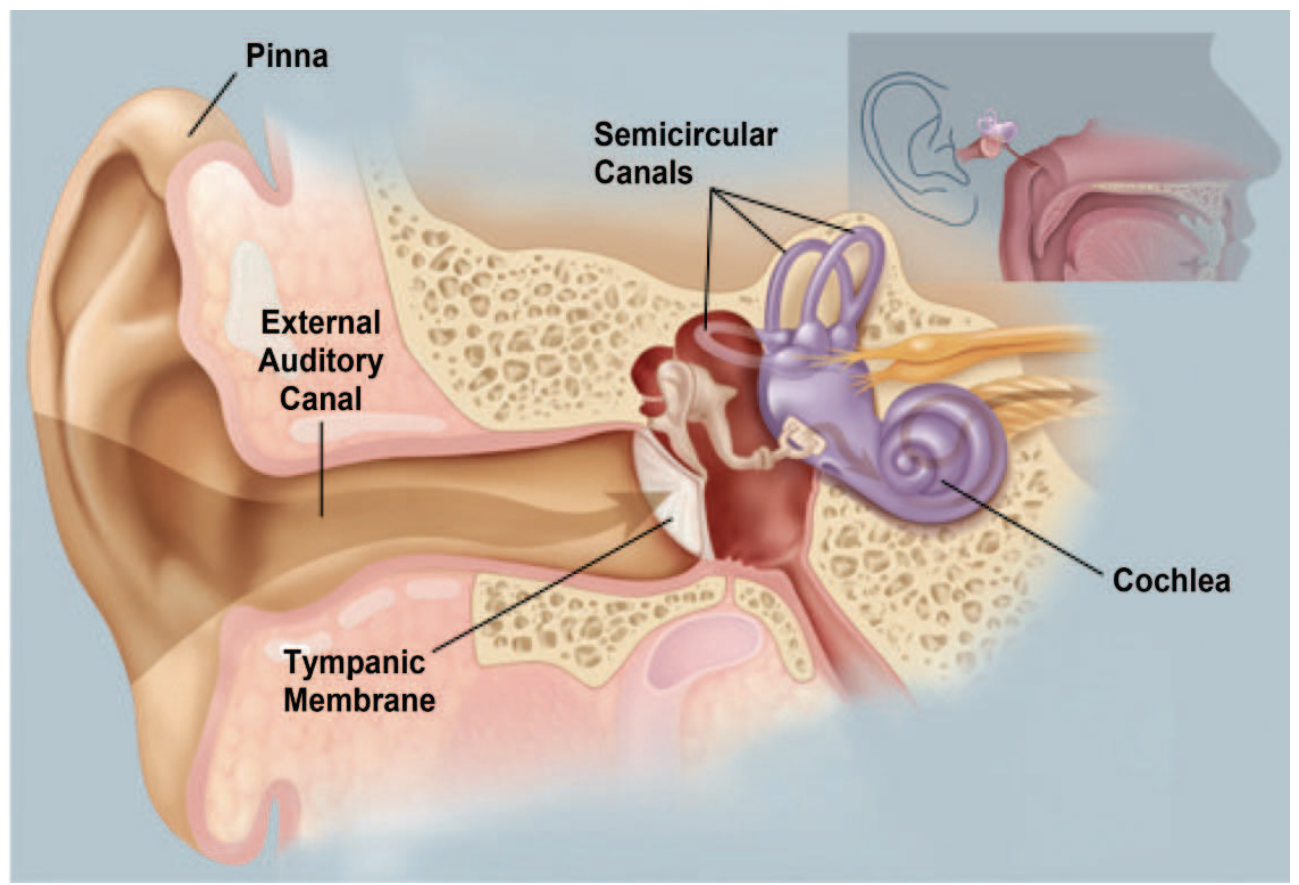

Fig. 1. Anatomical Diagram of the Ear (C) 2009 WebMD, LLC. All rights reserved.

\subsection{Physiology of hearing}

Sound in the form of air waves arrives at the auricle and is transmitted through the external auditory canal. Sound then causes the tympanic membrane to vibrate. Vibration energy in the tympanic membrane is transmitted through the ossicles to the oval window into the cochlea. Pressure vibrations are transmitted into the scala vestibuli and into the cochlea. Vibrations of the scala vestibuli are greatest at the location where the resonance frequency of the cochlea corresponds to the frequency of the transmitted sound waves. In this way, a topographic representation of sound is possible. The basilar membrane vibrates which 
causes deflection of the stereocilia, and stimulation of the cochlear nerve. Injury to middle ear causes hearing loss. The is due to the problem of impedance: the resistance of transfer of energy between two media. This can be understood by analogy with transmission of light through water. When sun shines on water some of the light is reflected, while the remaining is transmitted through the water. This is manifested as a glare on top of the water and also visibility below the surface. Without the middle ear, most of the sound would bounce off of the surface of the oval window and less sound would be transmitted into the cochlea. This is because sound must pass from one medium (air) into another (liquid) in order to stimulate the cochlea.

The middle ear reduces the problem of impedance mismatch through several mechanisms. The effective ratio of these areas of the tympanic membrane to the oval window is about 14:1 (Roger and Maurice 1992). A second mechanism by which the middle ear overcomes impedance mismatch is through the ossicles. The malleus is 1.3 times longer than the incus. The ossicles also constitute a lever mechanism with a mechanical advantage of 1.3:1 (Roger and Maurice 1992, Lee KJ 1995). The product of these areas and lever ratios represent the transfer ratio of the whole mechanism. $14 \times 1.3=18: 1$ (Roger and Maurice 1992). The vibration of cochlea fluids are processed and analyzed in such a way that data representing frequency, intensity and phase are transmitted as impulses along the auditory nerve via auditory pathway to brain for interpretation (Gibson 1978).

Thus injury to either the tympanic membrane or the middle ear ossicles from trauma will result in loss of this physiological function causing impedance mismatch ultimately resulting in impaired hearing (Roger 1992, Lee KJ1995).

The ear can be stimulated either with sound pressure waves or via vibrations applied directly to the skull. The latter is noted on audiograms as bone conduction and is used to distinguish the sensorineural component of hearing. There are three mechanisms in which vibratory energy placed directed onto the skull will cause stimulation of the cochlea:

This can be through

i. Distortional

ii. Inertia-Ossicular

iii. Osseo-tympanic mechanism

1. The distortional mechanisms is due to vibration directly distorting the skull. As the cochlea is part of the skull, it would be distorted as well. Because the round window yields more than the oval window, the scala vestubuli and scala tympani have different compliances. This results in the deflection of the basilar membrane and deflection of steriocillia with stimulation of the auditory nerve. However in fractured temporal bone (longtitudinal or transverse fracture) affecting either the oval window, cochlea or semicircular canal, this smooth mechanism is interrupted (Stanley 2009)

2. The inertial-ossicular mechanism of conductive hearing relates to the ability of vibration energy directed to the skull to cause motion of the ossicles. Vibration to the skull will cause the ossicles to move. Ossicular movement imparts its energy to the oval window which stimulates the cochlea. However, this is dependent on the direction of vibrations in the skull. If the direction of vibration is parallel to the axis of the movement of the ossicles, inertial-ossicular mechanism of conductive hearing takes place. If there is is 
temporal bone injury resulting in fracture of the temporal bone or ossicular joint, fracture results in change or loss in the axis of ossicular movement and causes conductive hearing loss. If the vector of skull vibration is perpendicular to the axis of the movement of the ossicles, the effect is negligible. As a vibrating object, the ossicles have a resonance frequency. Therefore the inertial-loss mechanism of conductive hearing is more prominent about the resonance frequency of the ossicles.

3. The osseo-tympanic mechanism of bone conductive hearing is best illustrated by occlusion of the external auditory canal. Occlusion may be as a result of pathologic conditions such as fracture to the temporal bone with blood clots occluding the external auditory canal or cerumen impaction. Vibration energy is transmitted through the skull, causing a vibration of the soft tissues of the external auditory canal. This vibratory energy is transmitted into the air of the external auditory canal. Some energy escapes the external auditory canal while some reaches the tympanic membrane. The tympanic membrane is thus stimulated; energy is transferred to the ossicles and onwards to the cochlea. This explains why when the external ear canal is occluded, the boneconduction threshold improves. Vibration energy into the external auditory canal bounces back from the object occluding the external auditory canal. Less sound energy is lost and more is reflected onto the tympanic membrane.

\subsection{Aetiopathogenesis}

Hearing loss due to trauma is a common phenomenon worldwide. This could arise from assaults, road traffic injury, domestic, industrial and sports injuries. These are relatively on the increase in our society. Trauma to the head causing conductive hearing loss commonly involves the external ear, middle ear and temporal bone in road traffic injuries. The sources of injury or accidents most frequently encountered are those involving motor vehicles; however, industrial and athletic injuries may also present potential lesions to the temporal bone and middle ear. Appropriate use of safety devices, both in automobiles and in industrial and athletic activities, to protect the skull and head from trauma may eliminate or reduce many of these problems. However, compliance with advised safety precautions is often not adequate.

\subsection{External auditory canal injury}

Two types of injury are likely to involve the external auditory canal: blunt and penetrating trauma, thermal and caustic burns. Isolated blunt trauma to the ear canal is most often caused by the insertion of a foreign object into the ear to scratch the skin or to remove wax. The skin of the ear canal, particularly the anterior and inferior part of the canal, is quite thin, with a minimal sub-epithelial layer. The tender skin of this portion of the canal is easily abraded and will bleed readily, particularly if the patient is on anticoagulant or anti-platelet therapy. In most instances, the pain and the sight of blood from the ear canal cause the patient to seek medical attention. In some cases, however, a secondary infection develops, and pain, hearing loss, or infected drainage causes the patient to seek help. The canal should be gently cleaned using microscopic technique, and blood clots, debris, and wax should be removed. When the bleeding site has been identified, placing a small pledget of Gelfoam coated with antibiotic ointment over it can readily control the bleeding. Alternatively, Gelfoam soaked with topical thrombin can be applied to the bleeding site. In rare cases, the 
site must be cauterized and then packed with a Merocel wick. In contrast, the skin of the posterosuperior part of the canal is much thicker and is more resistant to abrasions and injuries. Posterior lacerations usually stop bleeding because the subepithelial layer is more developed; therefore, vessels in this area readily contract and clot off.( Mitchell KS 2003)

After cleaning of the canal under good illumination, the tympanic membrane is inspected to determine the extent of injury. If an injury to the middle ear or temporal bone is discovered, a complete neurotologic examination is performed to evaluate the patient. Audiometric assessment can also be done to assess the degree of hearing loss. Blunt injuries to the temporal bone typically result from the head being forced against a stationary object in a deceleration injury or from an object being thrown directly at the head. Most injuries involving this region occur as a result of a glancing blow to the temporal region.

Although soft tissue injuries to the auricle and canal occur, they are often accompanied by fractures of the external auditory canal, middle ear structures, otic capsule, or surrounding structures. Mandibular injuries, particularly those that drive the mandible posteriorly into the jaw joint, will occasionally fracture the anterior wall of the ear canal, resulting in laceration of the skin and exposure of bone. Following blunt trauma to the ear and temporal bone, the external auditory canal should be carefully cleaned and bleeding controlled as described earlier. If exposed bone is found, it should not be debrided at this point but rather assessed later when the canal has healed. Radiographs, including facial bone computed tomographic (CT) scans and pantomographic mandibular views, should be obtained in these patients to define the injuries.

Occasionally, a direct blow to the auricle results in an isolated fracture of the external auditory canal and mastoid process. This is a fracture not involving the deeper parts of the temporal bone that are in contact with the dura matter. Regardless of where the fracture has occurred, the clinician should be aware that squamous cell epithelium can be entrapped by the fracture fragments, leading to the development of a canal cholesteatoma. Canal fractures can also lead to chronic infection, bone sequestration, and stenosis of the canal. The development of any of these sequelae may necessitate surgical débridement, grafting, reconstruction, or meatoplasty to ensure a healthy open ear canal. Penetrating injuries of the external auditory canal are usually caused by gunshot or stab wounds. This may be anteriorly through the parotid gland which often involves the external auditory canal or posteriorly through the mastoid bone also involving the external auditory canal. As a consequence, facial nerve injury, tympanic membrane perforation, and ossicular dislocation can result from gunshot wounds of the external auditory canal.

The facial nerve is most likely to be injured at the stylomastoid foramen apparently because it is relatively fixed at that point. In the absence of any of these additional injuries (mastoid or parotid) gunshot wounds of the ear canal require cleaning, a light dressing, and prophylactic antibiotics. Occasionally, the canal must be stented using Silastic with sofratulle protection with steroid based antibiotic drop impregnated in it or sofratulle with steroid based antibiotic impregnated rolled and stuck into the canal. Lacerations of the external auditory canal can occur either anteriorly or posteriorly and are often accompanied by partial avulsion of the auricle. These patients should be carefully evaluated for injury to the facial nerve and the great vessels; radiographic studies including arteriography may be indicated in these patients. Most external auditory canal lacerations require cleaning, gentle 
débridement, and suturing to realign the various parts of the ear canal and auricle. Surprisingly, stenosis does not usually occur in these patients.

Burns and caustic injuries to the ear canal often represent a potentially complicated situation in that severe burns can lead to circumferential scarring and stenosis of the canal. Most of these injuries are attributable to one of three mechanisms: a thermal burn, a caustic burn, or a welding injury. Thermal and caustic burns of the ear canal are usually associated with additional injury to the auricle, which may in itself lead to loss of cartilage, cicatrix formation, and stenosis of the canal. Most thermal burns of the ear canal are caused by flash injuries, fires, lightning strikes, or hot liquids such as oil. Similar to burns elsewhere on the body, the depth and extent of the burn should be determined and documented. Superficial thermal burns of the ear canal are usually treated with the application of antibiotic ointment. If more than half of the ear canal is involved or has third-degree burns, in addition to the application of antibiotic ointment, the canal is stented with soft Silastic tubing. Canal stenting is performed in an effort to prevent stenosis of the canal, which leads to the trapping of squamous debris and ultimately a destructive ear canal cholesteatoma. Stenosis of the canal is treated aggressively with corticosteroid injections, frequent dilations, and, in some cases, skin grafting or even meatoplasty. Caustic burns are usually caused by a chemical spill or a foreign object such as an alkaline battery. Thermal and acid burns cause coagulation necrosis, whereas alkaline burns cause liquefaction necrosis and leads to much more extensive injury over time (Mitchell KS 2003).

Kavanagh and Litovitz reported a series of battery-related injuries to the ear canal that were much more frequent and severe than expected, including tympanic membrane perforation, exposed bone of the ear canal, sensorineural hearing loss, ossicular destruction, and facial paralysis (Kavanagh KT and Litovitz $\mathrm{T}$ 1986). They also noted that otic drops must be withheld in these patients as they provide an external electrolyte bath for the battery, enhancing leakage and generation of an external current with subsequent tissue electrolysis and hydroxide formation. The foreign body should be removed as soon as possible, under general anesthesia if needed (Capo JM, Lucente FE 1986). Once the injury has been assessed, caustic burns are treated much like thermal burns described earlier, with microscopic cleaning, antibiotic eardrops, and stenting if indicated.

Welding injuries occur when hot slag or molten metal enters the meatus, usually resulting in either a small and localized burn of the ear canal or a tympanic membrane perforation. In most patients, microscopic cleaning, ciprofloxacin and hydrocortisone otic drops, and observation are the only measures indicated for welding injuries of the external auditory canal.

\subsection{Middle ear and Tympanic membrane injury}

The temporal bone and middle ear are composed of very dense bone. Relatively minor blows to the head would rarely cause a significant injury to the temporal bone and middle ear. The source of the injury that may involve the temporal bone must be of rather intense force.

The injury seen with trauma to the head may be either from two major categories: blunt trauma to the skull and penetrating trauma to the skull. The nature of the injury will vary considerably based on the type of trauma delivered directly to the head. The degree of 
hearing loss suffered by the patients also varies as discussed below. Trauma to the tympanic membrane and the middle ear can be caused by (1) overpressure, (2) thermal or caustic burns, (3) blunt or penetrating injuries, and (4) barotrauma. Of all these overpressure seems to be the most common. The major causes of overpressure include slap injuries and blast injuries. Slap injuries are extremely common and can be a result of either a hand or water slap. Slap injuries usually result in a triangular or linear tear of the tympanic membrane Most of these perforations cause mild hearing loss, aural fullness, and mild tinnitus. Blast injuries, although much less common in Nigeria, are potentially much more serious. Blast injuries may be caused by bomb explosions, gasoline explosions, rock blasting and air-bag deployment in automobile accidents. Blast injuries from bomb and gasoline explosions not only disrupt the tympanic membrane but also can cause temporal bone fracture, ossicular discontinuity, or high-frequency sensorineural hearing loss owing to cochlear injury. Following an overpressure injury, blood, purulent secretions, and debris should be carefully suctioned from the ear canal, and the perforation size and location should be recorded. Irrigation and pneumatic otoscopy should be specifically avoided in these patients. The ability to hear a whisper as well as tuning fork tests should be documented, and an audiogram should be obtained as soon as the patient's condition allows. A complete neurotologic examination should also be performed in these patients to document the status of the cranial nerves including the facial nerve and the vestibular nerve as well as the central nervous system. If the tympanic membrane perforation is dry, it should be observed and patient advised to keep the ear dry also ototopical ear drops are not indicated. If there is CSF leakage or mucopurulent discharge from the middle ear through the tympanic membrane perforation, the clinician should determine and note if this is consistent with cerebrospinal fluid (CSF). If a CSF leak is suspected, immediate CT scan of the temporal bone should be obtained to rule out a fracture. If the drainage is not consistent with CSF, oral antibiotics and ciprofloxacin with hydrocortisone otic drop should be applied in the form of wick dressing is done. A history of vertigo or nausea and vomiting and an audiogram showing a conductive hearing loss of more than $30 \mathrm{~dB}$ suggest disruption of the ossicular chain. Profound sensorineural loss also may signify oval window or cochlear damage.

Thermal injuries to the tympanic membrane include welding and lightning injuries. Welding injuries often result in non-healing perforations of the tympanic membrane, either as a result of infection or possibly because the slag acts to cauterize or devascularize the tympanic membrane as it passes through it. If infection occurs, the patient is treated with systemic antibiotics such as ciprofloxacin and steroid-based topical ear drops hydrocortisone otic drops. If the perforation is dry, it should be observed for a period of 12 weeks for spontaneous healing. If the drumhead does not heal, surgical closure in the form of tympanoplasty should be performed. Lightning and electrocution injuries are also a form of thermal injurie which are not rare, and the most frequent injury to the ear is perforation of the tympanic membrane ((Panosian MS, Dutcher 1994) The most common vestibular disturbance is transient vertigo. Other clinical findings include sensorineural hearing impairment, conductive hearing loss, tinnitus, temporal bone fracture, avulsion of the mastoid process, burns of the ear canal, and facial nerve paralysis (ogren and Edmund 1995). Management is similar to the welding injury as the tympanic membrane perforations caused by the lightning injury often do not heal, probably as a result of cauterization or devascularization of the tympanic membrane, much like welding injuries. 
Caustic injuries to the tympanic membrane can cause its perforation. With alkaline agents, the tympanic membrane is damaged by liquefaction necrosis, that is, the alkaline caustic penetrates the tympanic membrane, causing occlusion of the vasculature that may extend farther than the visible perforation.

As a result, the size of the perforation may not be fully appreciated until all of the inflammation is resolved. Furthermore, after caustic injuries, other middle ear pathologies observed include an extensive granulation reaction with scarification, ossicular fixation, chronic infection of the middle ear mucosa, canal blunting where the raw surfaces that surround the canal form a cicatrix, leading to narrowing of the ear canal and loss of the vibratory surface of the tympanic membrane. Other complications are chronic myringitis on the surface of the tympanic membrane, creating a raw weeping surface with granulation on the surface of the drumhead. Treatment involved the use of systemic antibiotics, steroidbased topical ear drops for aural dressing, audiologic assessment and a complete neurotologic evaluation to determine the extent of injury. When the ear has stabilized, and preferably when drainage has diminished, the middle ear and tympanic membrane can be reconstructed surgically.

In Nigeria compared to the developed world it is difficult to know the economic impact of this injury both financially and otherwise. It is estimated that the annual cost of dealing with this tragedy is more than $\$ 100$ billion in the USA. In a study done by the National Academy on Aging Society (NAAS) in 1999, it was found that the average value for time lost in a conductive injury due to trauma in the workplace costs more than US $\$ 8,000$. [NAAS 1999]. However this data are not available for the developing countries. Trauma patients consume more health care resources than heart and cancer patients combined, and whereas mortality from heart disease and cancer is declining, the incidence from trauma is increasing [Boden\&Galizzi 1999, Shires GT et al 1994].

Blunt trauma to the skull most frequently occurs as the result of the head being thrown against a solid or semisolid object, or an object being thrown directly at the head. Soft tissue injuries of the external auditory canal may occur with blunt trauma, particularly trauma that is glancing in nature, that is, delivered in a sharp angle to the side of the head as opposed to a 90-degree injury. Fractures of the middle ear structures, otic capsule, and structures surrounding the otic capsule may occur from blunt trauma. The most common form of temporal bone fracture, occurring from blunt trauma, is the longitudinal fracture of the temporal bone. It is estimated that $70 \%$ to $90 \%$ of temporal bone fractures are longitudinal (Cannon and Jahrsdoerfer, 1983; Dolan, 1989; Nelson, 1979). These fractures most commonly result from direct lateral blunt trauma to the skull in the parietal region of the head. In considering the effect of a fracture of the skull and its relationship to the temporal bone, it is helpful to think of the fracture occurring initially in a weaker portion of the calvarium, such as the squamous portion of the temporal bone, and the fracture line extending toward the temporal bone. Recognizing that the otic capsule is extremely dense bone, the fracture will occur around the otic capsule, taking the course of least resistance (Dahiya et al 1999. The course of least resistance usually involves major foramina in the skull base, the most common being that of the carotid artery and the jugular bulb. Fractures are frequently near the roof of the external auditory canal and run parallel along the petrous apex extending anteriorly to the foramen lacerum and the carotid artery. The line may also extend into the temporomandibular joint regions. 


\section{Methodology}

This is a retrospective review of 64 patients seen at the Ear, Nose and Throat clinic and the accident and emergency unit of the University of Ilorin Teaching hospital, Ilorin, Nigeria over a ten year period between January 1998 to Dec 2007. The patients had history of bleeding from the ear due to trauma from various causes. Patients with multiple traumas were also included and these had traumatic tympanic membrane perforation as part of the presentation. The data retrieved included the bio-data, the clinical presentation, source of injury, the clinical findings and the outcome of the patients. These were entered into an SPSS version 11.0 computer soft ware and analyzed descriptively.

\section{Results}

Seventy patients were found to have traumatic tympanic membrane perforation. However 6 individuals were excluded because of incomplete data. Thus only 64 patients' records were analyzed and formed the basis for this study. Age range of the patients was between 6 months to 50 yrs with a mean age of $29.2 \mathrm{yrs}$ and modal age of 35 years. About $5(7.9 \%)$ of them were $\leq 5 y e a r s$ and majority of the patients were between 35 and 50years of age (Table 1).

There were $46(71.9 \%)$ males and $18(28.1 \%)$ females with a male to female ratio of 2.5:1. Males were affected in most of the aetiologies except in "fall" where no male patient was recorded (table 2).

The commonest aetiology for trauma was from slaps, followed by road traffic injury (RTI) in $35.9 \%$ and $23.5 \%$ patients, respectively (Table 3 ).

Majority of the slap injury were from fights, security agents, senior students and cultist synonymous with Gangsterism (group of criminals especially those who are armed and use guns or group of students acting as terrorists within the school system.)at schools in $30.5 \%$, $17.4 \%$ and $17.4 \%$ respectively. (Table 4 )

Traumatic tympanic membrane perforation affected 36 left ears and 28 right ears. Majority of the patients (95\%) had associated sudden hearing loss. Tinnitus was present in $52 \%$ while $24(37.5 \%)$ of the patients had progression to chronic suppurative otitis media (Table 5). It was observed that majority of the patients failed to follow up clinical visits once the symptoms of bleeding and pain had subsided. An average of three follow up visits per patient was recorded. Out of the few \%that came for follow up check ups, only $7.8 \%$ had neo-membrane formation.

\begin{tabular}{ll}
\hline Age in years & Number \& Frequency (\%) \\
\hline 6months- 5yrs & $5(7.9 \%)$ \\
6years-10yrs & $1(1.6 \%)$ \\
11-20yrs & $15(23.5 \%)$ \\
21-34yrs & $19(29.7 \%)$ \\
35-64yrs & $24(37.7 \%)$ \\
\hline
\end{tabular}

Table 1. Age distribution of patients with traumatic TM perforations. 


\begin{tabular}{|c|c|c|}
\hline Predisposition & Male & $\begin{array}{l}\text { Frequency } \\
\text { Female }\end{array}$ \\
\hline Slap & 15 & 08 \\
\hline Instrumentation & 04 & 03 \\
\hline Self during ear cleaning & 05 & 02 \\
\hline RTI & 09 & 01 \\
\hline Foreign body & 10 & 03 \\
\hline Explosion & 03 & \\
\hline Fall & & 01 \\
\hline Total & 46 & 18 \\
\hline
\end{tabular}

Table 2. Predisposition and sex of patients.

\begin{tabular}{ll}
\hline Aetiology & Number \&Frequency (\%) \\
\hline Slaps & $23(35.9 \%)$ \\
Instrumentations & $7(10.9 \%)$ \\
Self Ear cleaning & $7(10.9 \%)$ \\
Road Traffic Injury & $15(23.5 \%)$ \\
Foreign body & $08(12.5 \%)$ \\
Explosions & $3(4.7 \%)$ \\
Falls & $1(1.6 \%)$ \\
\hline
\end{tabular}

Table 3. Aetiological profile of TM perforations.

\begin{tabular}{ll}
\hline Sources of slap & Number \& Frequency (\%) \\
\hline Security Agent & $4(17.4)$ \\
Assault from Fight & $7(30.5)$ \\
Spouse & $2(8.7)$ \\
Armed Robbery & $3(13.0)$ \\
Senior student/cultists & $4(17.4)$ \\
Sibling & $3(13.0)$
\end{tabular}

Table 4. Sources of Slaps.

\section{Discussion}

Trauma to the ear can be classified on the basis onf the anatomical location or the type of injury. This could be a simple blunt trauma to the pinna; laceration of the pinna, avulsion of part or the whole of the pinna; tympanic membrane perforation; dislocation of the ossicles; longitudinal and transverse fractures of the petrous temporal bone with 
associated loss of inner ear and facial nerve function (Ologe FE 2002, Toner JG \& Kerr AG 1997, Okafor BC 1983, Ijaduola GTA 1986, Bhattia PL 1987, Ladapo AA 1979, Ijaduola GTA and Okeowo PA 1986). Previous studies have shown that trauma to the tympanic membrane and the middle ear can be caused by overpressure (slap, fight, assault from security agents and road traffic injury (RTI)), thermal or caustic burns, blunt or penetrating injuries such as instruments and barotraumas (Mitchell K. S 2003, da LillyTariah OB and Somefun OA 2007). Overpressure is by far the most common mechanism of trauma to the tympanic membrane (Mitchell K. S 2003) in our environment. Traumatic perforation of the tympanic membrane may be caused by direct impact of fluids and direct pressure from outside.

The tympanic membrane (TM) is an important component of sound conduction as its vibratory characteristic is necessary for sound transmission in human beings (Richard R. G and Mark R.G 2003)

Traumatic tympanic membrane perforation findings from our study are similar to findings elsewhere from the world (Ologe FE 2002, Mitchell K. S 2003, da Lilly-Tariah OB and Somefun OA 2007). Male to female ratio was found to be $2.5: 1$ with high predominance among males $(72 \%)$. This is expected, as trauma is more common in this group of patients similar to other reported series (Ologe FE 2002, da Lilly-Tariah OB and Somefun OA 2007, Richard R. G and Mark R.G 2003). Our study of injury site indicated that the left ear is at a higher risk than the right ear in the ratio of 1.0:1.3 right to left which could be associated with the fact that most assailants were right handed, Thus it is likely that most of the acts of trauma such as slap occurred with the assailant and victims were facing each other making the left ear to be predominantly affected compared to the right side. Some of the causes of overpressure include slap injuries and blast injuries. Slap injuries are extremely common and can be result of either a hand or water slap and these injuries usually result in a triangular or linear tear of the TM (Mitchell K. S 2003). These slap injuries could be a product of fight or armed robbery attack. However, in our study it was found to be more common among the youth. In more than $50 \%$ of cases reviewed and those in the adult these cases were due to attack by the armed robbers or security agents. This was the highest cause of traumatic tympanic membrane perforation in our study as compared to a similar study in other regions of Nigeria where fight with spouse was the commonest aetiology recorded (da Lilly-Tariah OB and Somefun OA 2007). In contrast this type of injury made the least contribution in our study.

Slaps were the commonest type of violence seen between individuals, mostly between security agents and the offender followed by those among students. However, another study found tympanic membrane perforation resulting from slap from marital conflict between wife and husband (Mitchell K. S 2003). There is a need to educate the students and security agents on other punitive measure as there is predisposition to conductive hearing loss or an imminent chronic suppurative otitis media if not properly managed. Slap was commoner among males than in females similar to another study (Mitchell K. S 2003). Trauma to the temporal bone with fracture and leakage of cerebrospinal fluid into the middle ear causing conductive hearing losses was second common in this study and this was found to be secondary to road traffic injury. The management protocol for skull base fracture with TM perforation/CSF leakage does not require any intervention based on 
Otolaryngologist perspective to avoid contamination with an ascending infection. This was also found to be higher among male subjects compared to the females, perhaps associated with the role of males in African society as the bread winners, working outside home and thus are at a higher risk of various type of traffic injuries compared to women who predominantly stay at home. Attempt at removing foreign body, ear cleaning with variety of objects including cotton bud and wax removal in an unskilled manner either by the parents or the primary care physician with TM perforation was an important cause of hearing loss found mostly among children as previously reported (Ologe FE 2002, Toner JG \& Kerr AG 1997, Ladapo AA 1979, Ijaduola GTA and Okeowo PA 1986). There is a need for a primary care physician to provide patients with appropriate referral. Explosion is not a common phenomenon in our environment as the violence rate is still at a low level. Fall with perforation of tympanic membrane is an uncommon occurrence which has never been reported but was observed in a child, however the mechanism could not be explained.

Traumatic perforations often occur in healthy members of the community with generally an excellent prognosis (Toner JG \& Kerr AG 1997, Ijaduola GTA 1986). Healing with formation of neomembrane was observed only in five patients $(7.8 \%)$ and it is among the under five's this is not surprising as they are still growing.

\section{Conclusion}

Traumatic perforation of the tympanic membrane is still common in our environment. It affects all age groups, with more males affected than females. Slaps and RTI are the commonest aetiologies seen. The left ear is affected more than the right and sudden hearing loss is the most common presentation. There is a need to educate the students and security agents on alternative punitive measures and to discourage the act of unskilled removal of foreign body from the ear. Early identification, evaluation and referral of patients by primary care physician who see these patients will reduce the attendant morbidity.

\section{References}

[1] Bhattia, P.L. and Varughese,R. Pattern of Otolaryngological Diseases in Jos Community. Nig.Med.J. 1987; 17: 67-73.

[2] Boden LI, Galizzi M. Economic consequences of workplace injuries and illnesses: lost earnings and benefit adequacy. Am J Ind Med 1999;36:487-503.

[3] Capo JM, Lucente FE. Alkaline battery foreign bodies of the ear and nose. Arch Otolaryngol Head Neck Surg 1986;112:562-3.

[4] Challenges for the $21^{\text {st }}$ century Chronic disabling conditions NATIONAL ACADEMY ON AN AGING SOCIETY 1999;2:1-6

[5] Dahiya R, Keller JD, Litofsky NS, Bankey PE, Bonassar LJ, Megerian CA. Temporal bone fractures: otic capsule sparing versus otic capsule violating clinical and radiographic considerations. . J Trauma. 1999 Dec;47(6):1079-83

[6] da Lilly-Tariah OB, Somefun AO, Traumatic perforation of the tympanic membrane in University of Port Harcourt Teaching Hospital, Port Harcourt. Nigeria., Niger Postgrad Med J. 2007; 14 (2):121-4. 
[7] Ghoyareb B.Y, Yeakly J.W, Hall J.W, Jones E, Unusual complication of temporal bone fracture. Archive of otolaryngology head and Neck surgery. 1987;113: 749-53

[8] Gibson WR. Essentials of clinical electric response audiometry. Edinburgh: Churchill Livingstone, 1978: 133-56.

[9] Ijaduola, G. T.A. The Principles of Management of Deafness. Nig. Med. Pract. 1986; 12: 19-25.

[10] Ijaduola, G. T.A.; Okeowo P.A. Foreign body in the Ear and its importance: The Nigerian Experience. J. Trop. Paed. 1986; 32: 4-6

[11] Kavanagh KT, Litovitz T. Miniature battery foreign odies in auditory and nasal cavities. JAMA 1986; 255:1470-2

[12] Ladapo,A.A. Danger of foreign body in the ear Nig.Med. J. 1979; 9(1): 120-122.

[13] Lee KJ. Essential Otolaryngology- Head and neck surgery, 7th edition, Stamford. Appleton and Lange, 1995: 1- 66.

[14] Miller TR, Waehrer GM. Costs of occupational injuries to teenagers, United States. Inj Prev 1998;4:211-217.

[15] Mitchell KS 2003 Trauma to the Middle Ear, Inner Ear, and Temporal Bone in 2003: 14 ; 345-356 Ballenger's Otorhinolaryngology Head and Neck Surgery James B. Snow Jr, John Jacob Ballenger Sixteenth Edition BC Decker ISBN 1-55009-197-2 Inc Hamilton, Ontario L8N 3K7, Spain

[16] Ogren FP, Edmunds AL. Neuro-otologic findings in the lightning-injured patient. Semin Neurol 1995; 15:256-62.)

[17] Okafor, B. C. Otolaryngology in South Eastern Nigeria I: Pattern of Diseases of the Ear.Nig.Med.J. 1983; 13: 11-19.

[18] Ologe FE, Traumatic perforation of tympanic membrane in Ilorin, Nigeria Nig. J. Surg. 2002, Vol. 8 (1) :9-12

[19] Panosian MS, Dutcher PO. Transtympanic facial nerve injury in welders. Occup Med (Lond) 1994; 44:99-101).

[20] Peter JK, Paul HK, Principle of trauma in Byron J Bailey Head and Neck Surgery Otolaryngology 3rd edition Byron J, Karen H, Gerald B, Harold C, Jonas T, M. Eugene, Robert K, Anthony Pazos, Chri Gralapp Lippincott Williams \& Wilkins Publishers 2001;61:69 of 202.

[21] Podoshin L, Fradis M, Hearing loss after head injury. Archives of Otolaryngology. 1975;101:15-8

[22] Richard R. Gacek, Mark R. Gacek, Anatomy of the Auditory and Vestibular Systems, Ballenger's Otorhinolaryngology Head and Neck Surgery Sixteenth Edition James B. Snow Jr, John Jacob Ballenger published by DC Becker Inc, Ontario, 2003; 1: 1-5.

[23] Roger FG, Maurice H. Synopsis of Otolaryngology, 5th edition, London. ButterworthHeinemann Ltd.,1992: 3- 80.

[24] Shires GT, Thal ER, Jones RC, et al. Trauma. In: Schwartz SI, ed. Principles of surgery, 6th ed. New York: McGraw-Hill, 1994:175-224.

[25] Stanley A. Gelfand, Anatomy and Physiology of Auditory system in Essential of Audiology third edition thieme publisher, New York 2009 ;2: 77-78 google book assessed on 12/1/2012) 
[26] Toner, J. G. and Kerr A. G. Ear Trauma. Scott- Brown's Otolaryngology. Otology $6^{\text {th }}$ Edition Edited by J. B. Booth, General Editor Kerr, A. G. Advisory Editor Groves,J. Butterworths Meinemann, London 1997: 3/711-3/7/13. 


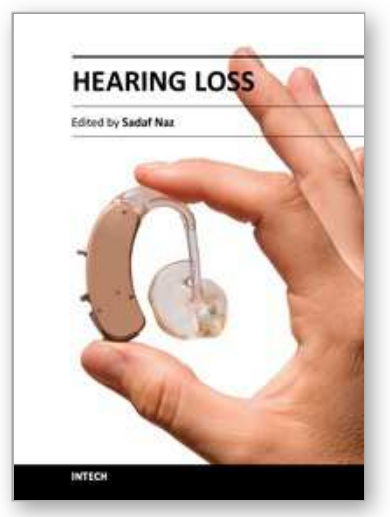

\author{
Hearing Loss \\ Edited by Dr. Sadaf Naz
}

ISBN 978-953-51-0366-0

Hard cover, 406 pages

Publisher InTech

Published online 28, March, 2012

Published in print edition March, 2012

Authored by 17 international researchers and research teams, the book provides up-to-date insights on topics in five different research areas related to normal hearing and deafness. Techniques for assessment of hearing and the appropriateness of the Mongolian gerbil as a model for age-dependent hearing loss in humans are presented. Parental attitudes to childhood deafness and role of early intervention for better treatment of hearing loss are also discussed. Comprehensive details are provided on the role of different environmental insults including injuries in causing deafness. Additionally, many genes involved in hearing loss are reviewed and the genetics of recessively inherited moderate to severe and progressive deafness is covered for the first time. The book also details established and evolving therapies for treatment of deafness.

\title{
How to reference
}

In order to correctly reference this scholarly work, feel free to copy and paste the following:

Olushola A. Afolabi, Biodun S. Alabi, Segun Segun-Busari and Shuaib Kayode Aremu (2012). Conductive Hearing Loss Due to Trauma, Hearing Loss, Dr. Sadaf Naz (Ed.), ISBN: 978-953-51-0366-0, InTech, Available from: http://www.intechopen.com/books/hearing-loss/-conductive-hearing-loss-due-to-trauma

\section{INTECH}

open science | open minds

\section{InTech Europe}

University Campus STeP Ri Slavka Krautzeka 83/A 51000 Rijeka, Croatia Phone: +385 (51) 770447

Fax: +385 (51) 686166 www.intechopen.com

\section{InTech China}

Unit 405, Office Block, Hotel Equatorial Shanghai No.65, Yan An Road (West), Shanghai, 200040, China 中国上海市延安西路65号上海国际贵都大饭店办公楼405单元 Phone: +86-21-62489820

Fax: +86-21-62489821 
(C) 2012 The Author(s). Licensee IntechOpen. This is an open access article distributed under the terms of the Creative Commons Attribution 3.0 License, which permits unrestricted use, distribution, and reproduction in any medium, provided the original work is properly cited. 